\title{
Angel-Wing Sign-What Goes Up Must Come Down
}

\author{
Elena Lanvers*, Hannah Henric-Petri and Eckhard Korsch \\ Kinderkrankenhaus,Amsterdamer, Strasse, Köln, Germany
}

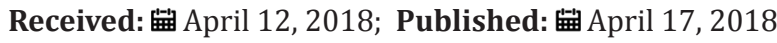

*Corresponding author: Elena Lanvers, Kinderkrankenhaus Amsterdamer Strasse, Amsterdamer Straße, Köln, NRW

Keywords: Pneumomediastinum; Angel-Wing Sign; CPAP-Ventilation; Respiratory Distress Syndrome; X-ray in Neonatology

\section{Case Report}

We report on a spontaneously delivered, female neonate, born in week $35+1$ of gestation, weighing $2230 \mathrm{~g}$. It was presented pale, hypotonic, without respiratory movement and a heart rate below $100 \mathrm{bpm}$. Therapeutic treatment started with bag-maskventilation, followed by the installation of a pharyngeal tube and CPAP-ventilation for a total of six hours applying a PEEP of 6 millibar. The X-ray displayeda pneumomediastinum, showing elevation of both thymus lobes in the sense of an angel-wing sign (also known as spinnaker-sail sign) [1-3] (Figure 1). Ending CPAPventilation, treatment continued vianasal cannula without oxygen supply for one more day, resulting in a stable respiratory status. The radiographic follow-up presented a noticeable regression of the pneumomediastinum (Figures $2 \& 3=6$ th day of life; part $\mathrm{C}=$ 13th day of life), which made invasive measures redundant.

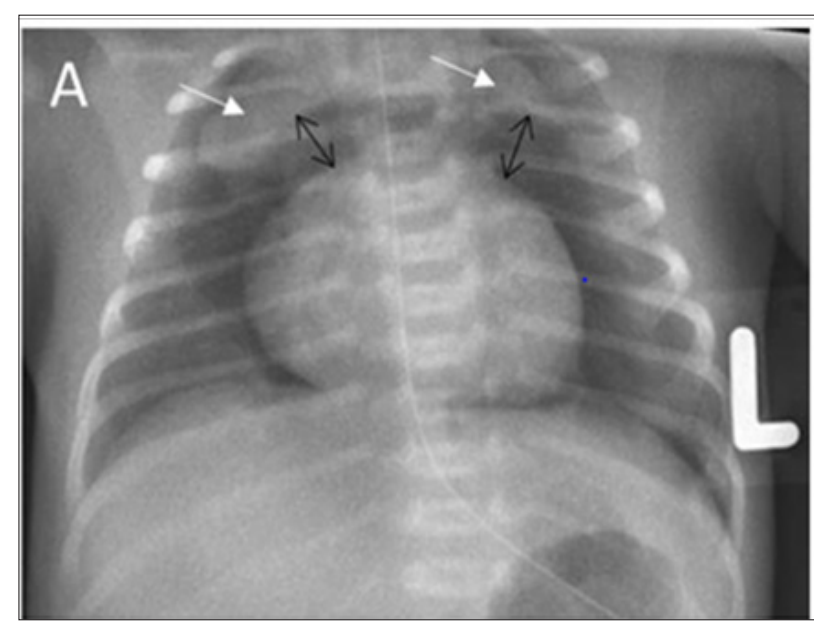

Figure 1: Part A-what goes up: Supine chest roentgenogram of the infant on the day of birth. Angel-wing sign (white arrows) shown as upward and lateral displacement of the thymus (black arrows).

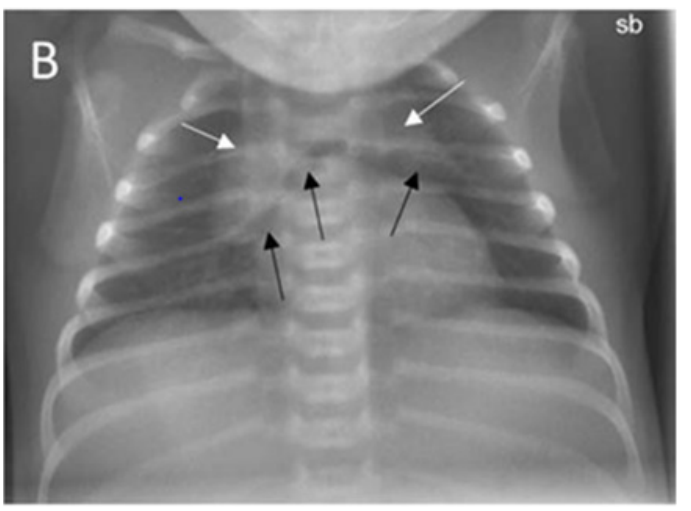

Figure 2: Parts B and C- must come down: Follow-up on day six (B) and thirteen of life (C) showing a noticeable regression of radiologic findings

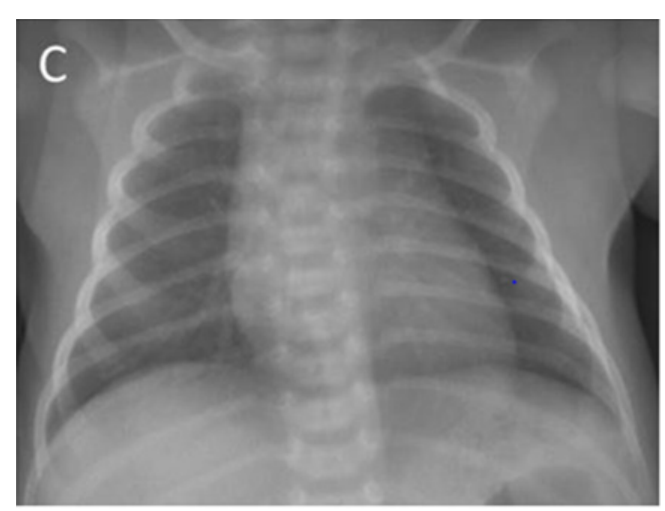

Figure 3: Parts B and C - must come down: Follow-up on day six (B) and thirteen of life (C) showing a noticeable regression of radiologic findings

The angel-wing sign is pathognomonic for pneumomediastinum [1]. The wedged-shaped accumulation of air in the mediastinum is caused by applying positive pressure ventilation. Gas is displaced 
from interstitial emphysema of the lungs, leading to an upward and lateral shift of thymic tissue [1,2]. Complications such as pneumothorax, pneumo pericardium or pneumoperitoneummay rarely occur [3]. Because of new Neonatal Resuscitation Program guidelines recommending continuous positive airway pressure (CPAP) for infants born with respiratory distress, a significant increase in CPAP use and radiographs [4] may raise the incidence of pneumomediastinum [5]. In accordance to the literature the presented case of a pneumomediastinum resolves without specific treatment and allows for conservative diagnostics and therapy [2].

Acknowledgement: Dedicated to Tom Petty $(† 2.10 .2017)$

\section{References}

1. Akin K, Cizmeci MN, Kanburoglu MK, Akelma AZ, Tatli MM (2013) Angel wing sign in a neonate with pneumomediastinum. J Pediatr 163(1): 296.

2. Correia Pinto J, Henriques Coelho T (2010) Images in clinical medicine. Neonatal pneumomediastinum and the spinnaker-sail sign. N Engl J Med 363(22): 2145.

3. Bejvan SM, Godwin JD (1996) Pneumomediastinum: old signs and new signs. Am J Roentgenol 166(5): 1041-1048.

4. Hishikawa K, Goishi K, Fujiwara T, Kaneshige M, Ito Y, et al. (2015) Pulmonary air leak associated with CPAP at term birth resuscitation. Arch Dis Child Fetal Neonatal Ed 100(5): F382-387.

5. Sherlock LG, Wright CJ (2017) 50 Years Ago in The Journal of Pediatrics: Pneumomediastinum, a Silent Lesion in the Newborn. J Pediatr. 183: 93.

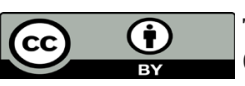

This work is licensed under Creative Commons Attribution 4.0 License

To Submit Your Article Click Here:

Submit Article



